ANNALES

UNIVERSITATIS MARIAE CURIE-SKŁODOWSKA

LUBLIN - POLONIA

VOL. LXIX, 1-2

SECTIO AA

2014

\title{
Thermal behaviour of light lanthanide(III) complexes with 2,3-pyridinedicarboxylic acid
}

\author{
Zofia Rzączyńska ${ }^{\mathrm{a}}$, Anna Danczowska-Burdon ${ }^{\mathrm{a}}$ and Marek Drewniak ${ }^{\mathrm{b}}$ \\ ${ }^{a}$ Department of General and Coordination Chemistry, \\ Faculty of Chemistry, Maria Curie-Skłodowska University, \\ M. Curie-Skłodowska Sq. 2, 20-031 Lublin, Poland \\ ${ }^{b}$ Central Laboratory, Faculty of Chemistry, Maria Curie-Skłodowska University, \\ M. Curie-Skłodowska Sq. 3, 20-031 Lublin, Poland \\ e-mail:*z.rzaczynska@poczta.umcs.lublin.pl
}

The lanthanide(III) complexes with 2,3-pyridinedicarboxylate ligand (PDC) were obtained as crystalline compounds from the water solutions. These compounds form the series of $\mathrm{Ln}_{2}(\mathrm{PDC})_{3} \cdot \mathrm{nH}_{2} \mathrm{O}$. All compounds are stable in air and insoluble in both water and common organic solvents. The hydrated complexes have been characterized by elemental analysis, thermal analysis (TG/DSC/DTA, and TG-FT-IR), FT-IR spectroscopy and X-ray analysis. 2,3-pyridinedicarboxylates of lanthanides(III) are stable in air below 313-323 K. Upon heating, hydrated complexes lose crystallization and lattice water in two steps. The values of dehydration enthalpy complexes are calculated from the DSC curves. The anhydrous compounds are stable at the temperature from $473 \mathrm{~K}$ to about $623 \mathrm{~K}$ and when heated they decompose to lanthanide oxides. Thermal and spectroscopic studies are essential for further studies and classification of compounds as MOF-like structures.

Keywords: Lanthanides, coordination polymer, 2,3-pyridinedicarboxylates, thermal behaviour. 


\section{INTRODUCTION}

Design and synthesis of metal-organic coordination polymers in the field of coordination chemistry and crystal engineering have been of great interest in view of their intriguing variety of architectures and potential applications. There is a considerable number of publications on the coordination metal-organic complexes with the ligands originating from the isomers of pyridinedicarboxylic acid [1-6]. These ligands are interesting because they contain different coordinating groups two carboxylate groups with their oxygen donor atoms and a nitrogen atom of pyridine ring. The carboxylate groups of ligands act in different modes in metal ion coordination as a bidentate bridging, bidentate chelating, threedentate chelating-bridging or monodentate so the complexes can have different structures either polymeric, dimeric and monomeric. The synthesis and physico-chemical properties of pyridine derivative ligands are important because a diversity of coordinating structures can be formed, including solid coordination polymers and their numerous applications in material chemistry, catalysis, luminescence and magnetochemistry [7-12 ].

Because of their donor sites the 2,3-pyridinedicarboxylic also called quinolinic acid [13-18] as one of six isomers of pirydinedicarboxylic acid, has found application as the ligand for metal complexes preparation. Generally, the metal-organic coordination complexes of this acid, can be divided into two or three categories: those based on transition metal motifs, those based on lanthanide motifs and lanthanide-transition metal heterometallic coordination polymers. In each type of the complexes there are those with one type of ligands as linkers and those with two or more different types of ligands linking the metal ions [6].

In the structure of d-metal quinolinate complexes the metal ions, as the coordination centre, have the coordination number 6 for example Cd(II) [19, 20], Zn(II) [20-23], Mn(II) [21, 24, 25], Co(II) [21, 26]; Ni(II) $[21,23], \operatorname{Ag}(\mathrm{I})$ [27] and in some cases coordination number $(\mathrm{CN})$ is 4 for example in the copper(II) [28] or Ag(I) [29] complexes. Nitrogen donor atom of pyridine ring always takes part in coordination of transition metal ions, but behaviour of each of two carboxylic groups of ligands is different in the structures of complexes. In the coordination metal ions there can sometimes take part only one carboxylate group of ligand. It might be monodentate $[19,21,25,27,28]$ or bidentate by two oxygens atoms [29] or by only one oxygen atom [20]. When two carboxylate groups take part in metal coordination, they can be either monodentate 
$[19,25,28]$ or bidentate $[20,24,28]$. Often, one group is mono- and the other is bidentate $[25,29,30]$. In each of the complexes pyridinedicarboxylic ligands have a bridging character and therefore polymeric structures are formed. Similarily, diferent ways of carboxylic group coordination occur in the heterometallic-centric quinolinate complexes of $\mathrm{Cu}-\mathrm{Mn}$ [28], $\mathrm{Cu}-\mathrm{Na}$ [28], Co-Na [26], Zn-UO2 [22] as well as in the metal complexes with two different ligands as linkers of metal ions [22, 26].

Lanthanide(III) ions which have higher and variable coordination numbers $(\mathrm{CN})$ 8, 9 or 10 [31] apart from main, larger organic ligands for example pyridinedicarboxylate ligands they coordinate with ancillary ligands e.g. water or other solvent molecules. In contrast to d-electronic metal ions, lanthanide ions, as the strong Lewis acids coordinate rather to oxygen than to nitrogen donor atoms. Carboxylic groups through oxygen atoms bond metal ions in a different manner but very often they are chelating. [30, 32]. In the hetero-metallic 4f-3d complexes with the quinolinic ligand, each of the metal ions supplements its $\mathrm{CN}$ : $3 \mathrm{~d}$ ions to 6 , 4f ions to 8 or 9 , by bonding the ancillary, small ligands. Structures of these compounds depend on the type of solvent, metal-ligand ratio, temperature and $\mathrm{pH}$ of synthesis [33, 34]. The ligands, which supplement the coordination sphere of metal ions for example water molecules, DMSO and so on, can be easily removed from the coordination sphere without the lanthanide-organic framework collapse. This inspires the research groups to seek the porous lanthanide-organic frameworks using pyridinedicarboxylate ligands as rigid ones. These ligands can adopt different conformations in the complex structure. It is important to choose proper organic ligands for the structural features construction. This work is part of our systematic study on different series of lanthanide(III) aromatic pyridinedicarboxylates. Recently a systematic study on lanthanide(III) 2,4-pyridinedicarboxylates [35], 2,5-pyridinedicarboxylates [36] and 3,5-pyridinedicarboxylates have been carried out [37].

This investigations presented the synthesis and thermal stability of lanthanide(III) 2,3-pyridinedicarboxylate complexes.

\section{EXPERIMENTAL}

\subsection{Materials}

All chemicals employed were commercially available from Aldrich Company and used without further purification. 2,3-pyrydinedicarboxylic acid (quinolinic acid) $99 \%$ purity was obtained from Aldrich. 


\subsection{Sample Preparation}

2,3-pyridinedicarboxylates of lanthanides(III) were prepared in water solution by adding ammonium salt of ligand to each lanthanide(III) chloride at $60^{\circ} \mathrm{C}$ with continuous stirring. In the case of cerium(III) compound cerium(III) nitrate was used for the synthesis. The precipitates were left for recrystallization for about 1-2 hours. After that, the precipitates were filtered, washed with water to eliminate ammonium ions and dried at $303 \mathrm{~K}$ under atmospheric pressure.

Lanthanide(III) chlorides for the synthesis were prepared in the standard way. The corresponding oxides (except for cerium) $(0.5 \mathrm{~g}$ of each oxide) were treated with concentrated hydrochloric acid and the resulting solutions were evaporated close to dryness, next redissolved in water and again evaporated close to dryness to eliminate the excess of hydrochloric acid. This procedure was repeated to obtain $\mathrm{pH}$ 5.8. After that the solutions were transferred to the volumetric flask and diluted to the volume of $30 \mathrm{~cm}^{3}$. The solutions of lanthanide(III) chlorides were about $0.1 \mathrm{M}$.

The ammonium salt was prepared by adding the solution of $\mathrm{NH}_{3} \cdot \mathrm{H}_{2} \mathrm{O}$ to the suspension of about $1 \mathrm{~g}$ of acid in $50 \mathrm{~cm}^{3}$. The amount of acid was stoichiometric towards each oxide $(0.5 \mathrm{~g})$.

Disodium salt of the acid (necessary as the defined reference at the IR spectroscopy) $\mathrm{Na}_{2} \mathrm{C}_{5} \mathrm{H}_{3} \mathrm{~N}(\mathrm{COO})_{2} \cdot \mathrm{H}_{2} \mathrm{O}$ was prepared by the reaction of stoichiometric amounts of the acid $(0.005 \mathrm{~mol}, 0.835 \mathrm{~g})$ and sodium hydroxide; $(0.001 \mathrm{~mol} ; 0.040 \mathrm{~g})$. The solution of $\mathrm{pH} 7$ was dried at $303 \mathrm{~K}$ to obtain the crystalline substance.

\subsection{Physical Techniques}

The FT-IR spectra were recorded with the 1725 Perkin Elmer spectrometer in the range of $4000-400 \mathrm{~cm}^{-1}$ using the $\mathrm{KBr}$ technique.

Thermogravimetric analyses were conducted on the Setsys 16/18 analyzer in dynamic air atmosphere. Therefore, 6.87-8.0 mg samples were heated in the range of 303-1273 $\mathrm{K}$ in the ceramic crucibles using the heating rate of $10 \mathrm{~K} \mathrm{~min}^{-1}$. The TG, DTA and DSC curves were registered. The elementary analysis was carried out using the CHN 2400 Perkin Elmer Analyzer. The water content was determined from the thermogravimetric curves of their mass loss and elementary analysis. The metal content was determined from the TG curves.

Gaseous products of decomposition were identified using a Netzsch TG 209 apparatus coupled to a Bruker FTIR 66 Spectrophotometer. The 
samples were heated in dynamic argon atmosphere with a rate of $20^{\circ} \mathrm{C} \mathrm{min}^{-1}$ up to $1000^{\circ} \mathrm{C}$ using a ceramic crucible.

Powder X-ray diffraction patterns (XRPD) hydrated complexes were studied using a HZG 4A2 diffractometer with $\mathrm{CuK}_{\alpha}$ radiation $\left(\lambda_{\alpha}=1.54187 \AA\right)$. The measurements were made in the range $2 \Theta=5-60^{\circ}$. For the representative complex $\mathrm{Sm}_{2}(\mathrm{PDC})_{3} \cdot 8 \mathrm{H}_{2} \mathrm{O}$, there were carried out powder X-ray diffraction experiments in situ at different temperatures using a PANalytical Empyrean ${ }^{\mathrm{TM}}$ diffractometer 777.

\section{RESULTS AND DISCUSSION}

\subsection{XRD Analysis}

The analytical data for the synthesized compounds are shown in Table 1. These results establish the stoichiometry of lanthanide(III) compounds, which are in agreement with the formulae $\mathrm{Ln}_{2}\left(\mathrm{C}_{5} \mathrm{H}_{3} \mathrm{~N}\right.$ $\left.(\mathrm{COO})_{2}\right)_{3} \cdot n \mathrm{H}_{2} \mathrm{O}$, where $\mathrm{Ln}$ is $\mathrm{La}, \mathrm{Ce}, \mathrm{Pr}, \mathrm{Nd}, \mathrm{Sm}, \mathrm{Eu}$ and $\mathrm{Gd}(\mathrm{III})$ and the number of water molecules is from 6 for $\mathrm{Eu}(\mathrm{III}), 9$ for $\mathrm{Nd}$ and $\mathrm{Gd}(\mathrm{III})$ and 8 for remaining complexes.

The XRD-diffraction patterns show that compounds in the series from $\mathrm{La}(\mathrm{III})$ to $\mathrm{Eu}(\mathrm{III})$ are crystalline while the $\mathrm{Gd}(\mathrm{III})$ complex is amorphous. The change of the properties in the lanthanide compounds series from $\mathrm{La}$ to $\mathrm{Lu}$, is observed in the middle series The disruption of the properties continuation sometimes takes place in the middle of the La$\mathrm{Gd}$ and Gd-Lu series and is called double-double effect [38]. That is probably why the Gd(III) complex changes its character from crystalline to amorphous.

\subsection{Infrared Spectroscopy}

The infrared spectroscopic data on 2,3-pirydinedicarboxylic acid, its disodium salt and the compounds with the lanthanide ions(III) considered in this study are shown in Table 2 . The investigation was focused mainly in the $1700-1400 \mathrm{~cm}^{-1}$ range, because this region is potentially the most informative in attempting to assign coordination sites. According to the data from the FT-IR spectra we can assume that both carboxylic groups in each light lanthanide(III) complex are deprotonated. In the experimental FT-IR spectra of lanthanide(III) quinolinates high intensity bands of $v_{\text {as }}\left(\mathrm{COO}^{-}\right)$vibrations appear at 1568 and 1592 for $\mathrm{La}(\mathrm{III}), 1572$ for $\mathrm{Ce}(\mathrm{III}), 1572$ and 1544 for $\mathrm{Pr}(\mathrm{III}), 1568$ for Nd(III), 1580 and 1552 for 


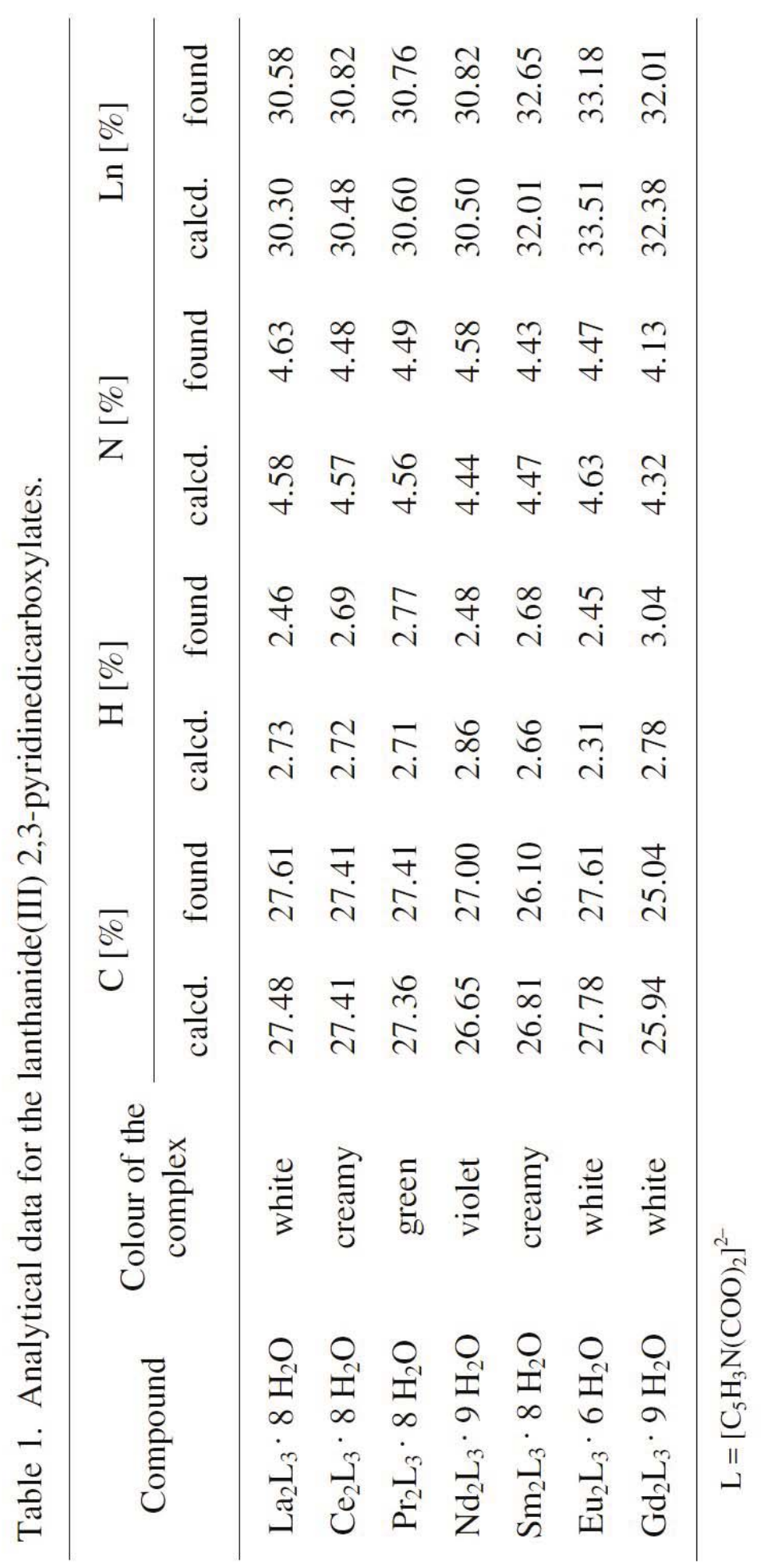




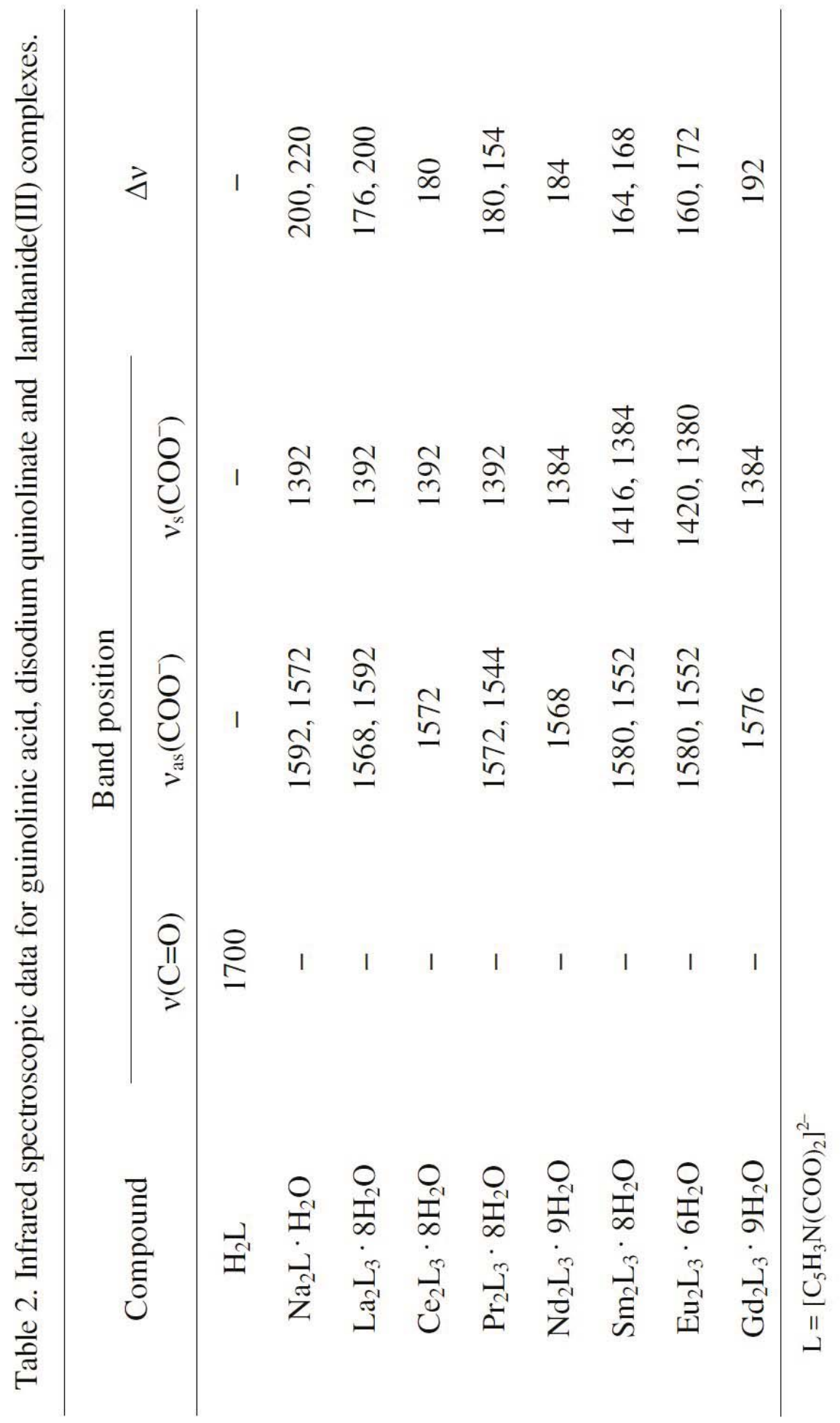


both $\mathrm{Sm}(\mathrm{III})$ and $\mathrm{Eu}(\mathrm{III})$ and $1576 \mathrm{~cm}^{-1}$ for Gd(III) complex respectively. The bands of $v_{\mathrm{s}}\left(\mathrm{COO}^{-}\right)$for those complexes are present at 1392 for $\mathrm{La}(\mathrm{III})$ to $\mathrm{Nd}(\mathrm{III}), 1416$ and 1384 for $\mathrm{Sm}(\mathrm{III}), 1420$ and 1380 for $\mathrm{Eu}(\mathrm{III})$ and $1384 \mathrm{~cm}^{-1}$ for $\mathrm{Gd}(\mathrm{III})$ compounds. The values of $\Delta v$ estimated for disodium salt were 200 and $220 \mathrm{~cm}^{-1}$, while those for complexes are about 200 and $170-180 \mathrm{~cm}^{-1}$. The $\Delta v$ value for each lanthanide complex is the same and lower than that for disodium salt. It follows that carboxylate anions can be both bidentate chelating [32] and bidentate bridging [30] in these compounds. FT-IR spectra of lanthanide 2,3-pyridinedicarboxylates contain wide, intensive bands in the range of $3700-2800 \mathrm{~cm}^{-1}$ which correspond to the stretching $\mathrm{O}-\mathrm{H}$ vibrations from crystal water molecules.

\subsection{Thermal Analysis}

The thermal stability of the lanthanide compounds was studied and the results are presented in Table 3.

Table 3. Thermal data for light lanthanide(III) complexes and sodium salt with 2,3-pyridinedicarboxylate anion,

\begin{tabular}{|c|c|c|c|c|c|}
\hline \multirow{2}{*}{ Compound } & \multirow{2}{*}{$\begin{array}{c}\text { Dehydration } \\
\text { enthalpy value } \\
{\left[\mathrm{kJ} \mathrm{mol}^{-1}\right]}\end{array}$} & \multirow{2}{*}{$\begin{array}{c}\text { Range of } \\
\text { decomposition } \\
{[\mathrm{K}]}\end{array}$} & \multicolumn{2}{|c|}{$\begin{array}{c}\text { Weight loss } \\
{[\%]}\end{array}$} & \multirow{2}{*}{$\begin{array}{c}\text { Stable } \\
\text { products of } \\
\text { decomposition }\end{array}$} \\
\hline & & & calcd. & found & \\
\hline \multirow{2}{*}{$\mathrm{Na}_{2} \mathrm{~L} \cdot \mathrm{H}_{2} \mathrm{O}$} & \multirow{2}{*}{50} & $383-453$ & 7.86 & 8.16 & $\mathrm{Na}_{2} \mathrm{~L}$ \\
\hline & & $823-1023$ & 53.71 & 53.71 & $\mathrm{Na}_{2} \mathrm{CO}_{3}$ \\
\hline \multirow{3}{*}{$\mathrm{La}_{2} \mathrm{~L}_{3} \cdot 8 \mathrm{H}_{2} \mathrm{O}$} & \multirow{3}{*}{270} & $313-473$ & 15.71 & 15.87 & $\mathrm{La}_{2} \mathrm{~L}_{3}$ \\
\hline & & $663-753$ & 50.06 & 49.35 & $\mathrm{La}_{2} \mathrm{O}_{2} \mathrm{CO}_{3}$ \\
\hline & & $753-1023$ & 64.46 & 64.13 & $\mathrm{La}_{2} \mathrm{O}_{3}$ \\
\hline \multirow{3}{*}{$\mathrm{Ce}_{2} \mathrm{~L}_{3} \cdot 8 \mathrm{H}_{2} \mathrm{O}$} & \multirow{3}{*}{260} & $303-388$ & 5.87 & 5.08 & $\mathrm{Ce}_{2} \mathrm{~L}_{3} \cdot 5 \mathrm{H}_{2} \mathrm{O}$ \\
\hline & & $388-448$ & 15.66 & 15.80 & $\mathrm{Ce}_{2} \mathrm{~L}_{3}$ \\
\hline & & $598-673$ & 62.57 & 62.14 & $\mathrm{CeO}_{2}$ \\
\hline \multirow{3}{*}{$\mathrm{Pr}_{2} \mathrm{~L}_{3} \cdot 8 \mathrm{H}_{2} \mathrm{O}$} & \multirow{3}{*}{300} & $303-353$ & 15.63 & 15.51 & $\mathrm{Pr}_{2} \mathrm{~L}_{3}$ \\
\hline & & $618-718$ & 49.87 & 48.60 & $\mathrm{Pr}_{2} \mathrm{O}_{2} \mathrm{CO}_{3}$ \\
\hline & & $718-838$ & 63.04 & 62.83 & $\operatorname{Pr}_{6} \mathrm{O}_{11}$ \\
\hline
\end{tabular}


Cont. Table 2.

\begin{tabular}{|c|c|c|c|c|c|}
\hline \multirow{3}{*}{$\mathrm{Nd}_{2} \mathrm{~L}_{3} \cdot 9 \mathrm{H}_{2} \mathrm{O}$} & \multirow{3}{*}{245} & $303-368$ & 15.53 & 15.82 & $\mathrm{Nd}_{2} \mathrm{~L}_{3}$ \\
\hline & & $368-403$ & 50.45 & 50.54 & $\mathrm{Nd}_{2} \mathrm{O}_{2} \mathrm{CO}_{3}$ \\
\hline & & $618-738$ & 64.41 & 64.05 & $\mathrm{Nd}_{2} \mathrm{O}_{3}$ \\
\hline \multirow{4}{*}{$\mathrm{Sm}_{2} \mathrm{~L}_{3} \cdot 8 \mathrm{H}_{2} \mathrm{O}$} & \multirow{4}{*}{200} & $303-373$ & 9.57 & 9.61 & $\mathrm{Sm}_{2} \mathrm{~L}_{3} \cdot 3 \mathrm{H}_{2} \mathrm{O}$ \\
\hline & & $373-423$ & 15.32 & 14.87 & $\mathrm{Sm}_{2} \mathrm{~L}_{3}$ \\
\hline & & $618-748$ & 56.54 & 56.34 & $\mathrm{Sm}_{2} \mathrm{O}_{2} \mathrm{CO}_{3}$ \\
\hline & & $823-908$ & 62.89 & 62.13 & $\mathrm{Sm}_{2} \mathrm{O}_{3}$ \\
\hline \multirow{4}{*}{$\mathrm{Eu}_{2} \mathrm{~L}_{3} \cdot 6 \mathrm{H}_{2} \mathrm{O}$} & \multirow{4}{*}{185} & $303-373$ & 7.93 & 8.56 & $\mathrm{Eu}_{2} \mathrm{~L}_{3} \cdot 2 \mathrm{H}_{2} \mathrm{O}$ \\
\hline & & $373-413$ & 11.90 & 12.49 & $\mathrm{Eu}_{2} \mathrm{~L}_{3}$ \\
\hline & & $623-723$ & 51.49 & 51.93 & $\mathrm{Eu}_{2} \mathrm{O}_{2} \mathrm{CO}_{3}$ \\
\hline & & $748-948$ & 61.19 & 61.57 & $\mathrm{Eu}_{2} \mathrm{O}_{3}$ \\
\hline \multirow{3}{*}{$\mathrm{Gd}_{2} \mathrm{~L}_{3} \cdot 9 \mathrm{H}_{2} \mathrm{O}$} & \multirow{3}{*}{228} & $303-443$ & 16.67 & 17.01 & $\mathrm{Gd}_{2} \mathrm{~L}_{3}$ \\
\hline & & $643-733$ & 46.37 & 45.15 & $\mathrm{Gd}_{2} \mathrm{O}_{2} \mathrm{CO}_{3}$ \\
\hline & & $733-963$ & 62.68 & 63.11 & $\mathrm{Gd}_{2} \mathrm{O}_{3}$ \\
\hline
\end{tabular}

$$
\mathrm{L}=\left[\mathrm{C}_{5} \mathrm{H}_{3} \mathrm{~N}(\mathrm{COO})_{2}\right]^{2-}
$$

Mass loss was read from the TG curves of the complexes (Fig. 1). The mass loss for the investigated complexes was calculated in the temperature range $303-1273 \mathrm{~K}$. The TG analysis was also carried out to determine the kind of water molecules (lattice or coordination water) present in the obtained $\mathrm{Ln}$ (III) complexes. The complexes of light lanthanides(III) decompose in the similar way when heated. The TG and DTG curves consist of three decomposition steps at about 373, 673 and $773 \mathrm{~K}$. The accurate values of temperature and mass loss are given in the Table 3. On the basis of TG curves it is sometimes possible to distinguish the coordination water molecules from the crystalline water molecules, but mostly all molecules of water are released in one step. In the case of $\mathrm{Ce}(\mathrm{III}), \mathrm{Sm}$ (III) and $\mathrm{Eu}(\mathrm{III})$ complexes during the dehydration process at first 3, 4 or 5 molecules of crystalline water are released and next strongly bonded molecules in the inner coordination sphere are released. The $\mathrm{La}(\mathrm{III}), \mathrm{Pr}(\mathrm{III}), \mathrm{Nd}(\mathrm{III})$ and $\mathrm{Gd}(\mathrm{III})$ complexes release all molecules of water in one step. 

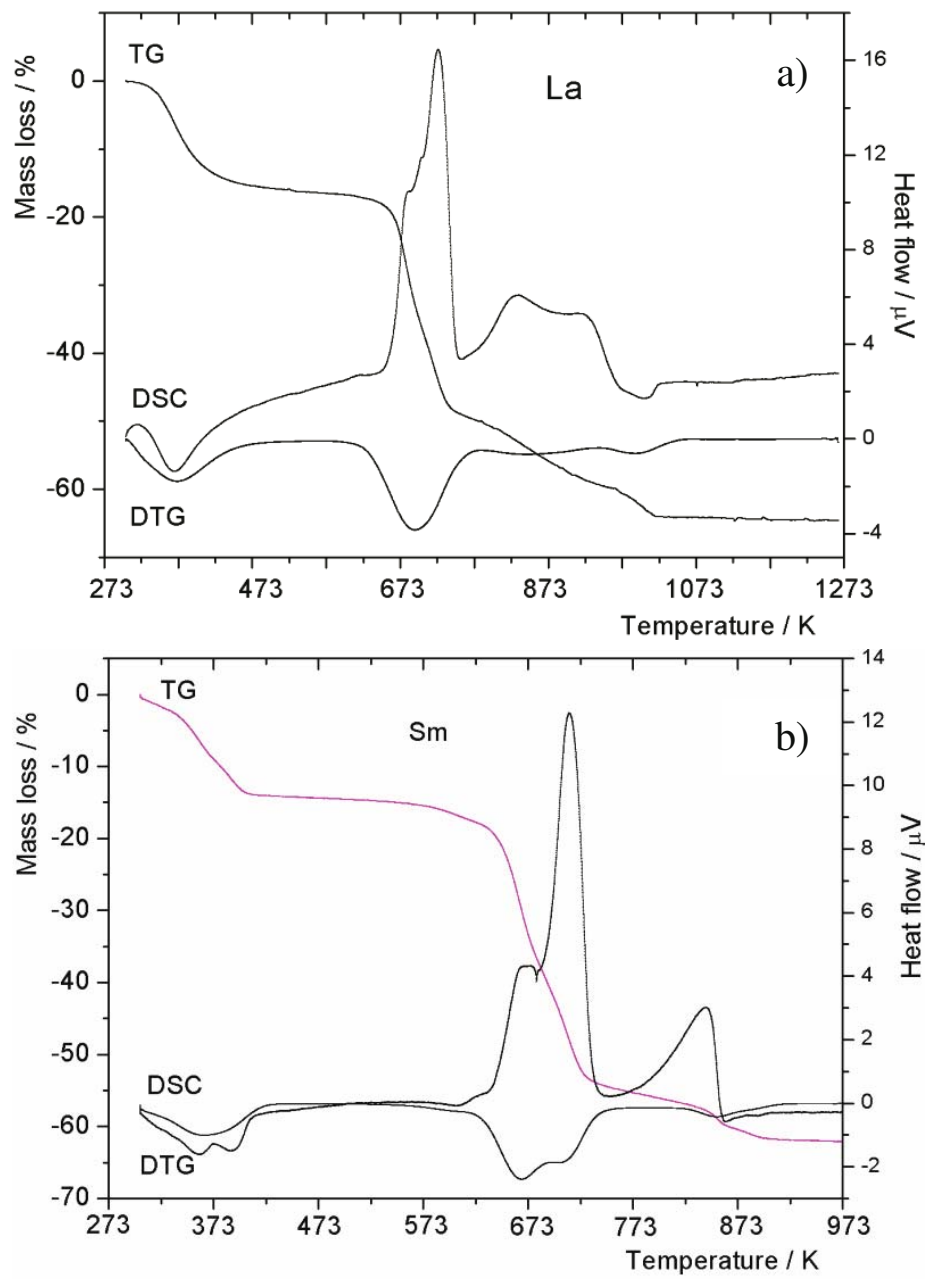

Fig. 1. TG, DTG and DSC curves for (a) $\mathrm{La}_{2} \mathrm{~L}_{3} \cdot 8 \mathrm{H}_{2} \mathrm{O}$ and (b) $\mathrm{Sm}_{2} \mathrm{~L}_{3} \cdot 8 \mathrm{H}_{2} \mathrm{O}$ complexes.

The values of dehydratation enthalpy is presented in Table 3 . The values were calculated from the values of the area under the peaks of the dehydration on the DSC curves. The values in $\left[\mu \mathrm{V} \mathrm{s} \mathrm{mg} \mathrm{m}^{-1}\right]$, were multiplied by the coefficient (for our apparatus equal to $0.0028 \mathrm{~J} \mathrm{mg}^{-1}$ ) which was experimentally found from the calibration of indium melting curve. The obtained values were recalculated for $\mathrm{kJ} \mathrm{mol}^{-1}$ of the compound. Larger value of dehydratation enthalpy for $\operatorname{Pr}(\mathrm{III})$ than for other complexes can be explained by irregularity of some properties in the lanthanide series, according to duble-duble effect [38]. 
The anhydrous phases of compounds are stable up to 623-673 K which one can see as the flat segment of the curves in the pictures (Fig. 1). Further heating causes the gradual decomposition of the complexes. The intermediate products of decomposition are oxocarbonate $\mathrm{Ln}_{2} \mathrm{O}_{2} \mathrm{CO}_{3}$ or mixture of oxocarbonate $\mathrm{Ln}_{2} \mathrm{O}_{2} \mathrm{CO}_{3}$ and lanthanide oxide(III) [40]. From the TG curves of complexes it is difficult to indicate the accurate mass loss connected with formation of oxocarbonates which starts at about $673 \mathrm{~K}$ and ends with oxide formation above $973 \mathrm{~K}$. The anhydrous cerium(III) complex decomposes strictly to the cerium oxide $\mathrm{CeO}_{2}$. Appropriate lanthanide oxides with the general formula $\mathrm{Ln}_{2} \mathrm{O}_{3}$, except for $\mathrm{CeO}_{2}$ and $\mathrm{Pr}_{6} \mathrm{O}_{11}$, are formed as final products of these complexes decomposition. Because of that the lanthanide(III) 2,3-pyridinedicarboxylate complexes have the similar thermal stability and exhibit a similar shape and course of TG curves, the investigations of $\mathrm{XRD}$ in situ in different temperatures were carried out only for the samarium(III) complex as the representative of the group. X-ray diffraction powder pattern of the hydrated complex at $303 \mathrm{~K}$ shows that the compound has a crystalline structure (Fig. 2).

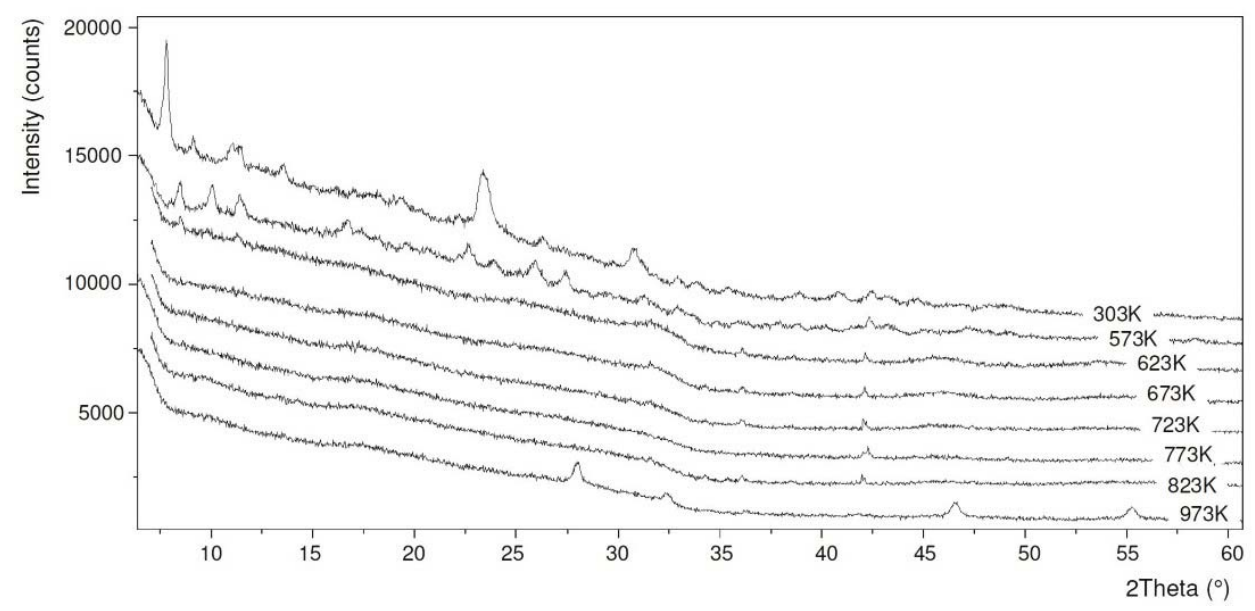

Fig. 2. XRD for $\mathrm{Sm}_{2} \mathrm{~L}_{3} \cdot 8 \mathrm{H}_{2} \mathrm{O}$ and its decomposition products.

Next, the sample was heated continuously with the rate $10 \mathrm{~K} \mathrm{~min}^{-1}$ to $573 \mathrm{~K}$ (TG curve show plateau after release of all water molecules at this temperature (Fig. 1b). The XRD pattern of the compound at $573 \mathrm{~K}$ is significantly different from that of the hydrated one but dehydration does not destroy the crystallinity of the complex. Further heating of sample with the same rate and XRD measurements at 623, 673, 723, 773, and $823 \mathrm{~K}$ shows that amorphous phases of complex degradation is formed 
which at $973 \mathrm{~K}$ are transformed in crystalline phase of samarium(III) oxide [ICDD 01-078-4055].

On the other hand, FT-IR spectrum of gas products decomposition of the $\mathrm{Nd}(\mathrm{III})$ complex, as the representative of the group, confirms water molecules release from $303 \mathrm{~K}$ to $418 \mathrm{~K}$ with the $\mathrm{vOH}$ bands vibrations in two frequency regions: $3900-3500 \mathrm{~cm}^{-1}$ and $1850-1300 \mathrm{~cm}^{-1}$. Next at about $550 \mathrm{~K}$ characteristic bands of $\mathrm{C}=\mathrm{O}$ vibrations from carbon dioxide appear. The bands in the region $3100-3050 \mathrm{~cm}^{-1}$ and $1650-1350 \mathrm{~cm}^{-1}$ (about $668 \mathrm{~K}$ ) were assigned to the stretching $\mathrm{C}-\mathrm{H}$ vibrations from hydrocarbons of organic ligand decomposition. In the range of lower frequencies two bands of different types were registered. First, the intensive one, appeared at $600 \mathrm{~K}$ and was assigned to the pyridine ring stretching vibrations $\left(698 \mathrm{~cm}^{-1}\right)$, while the second band, registered as the double band, was assigned to the $v(\mathrm{C}=\mathrm{O})$ vibrations $\left(670 \mathrm{~cm}^{-1}\right)$ (Fig. 3).

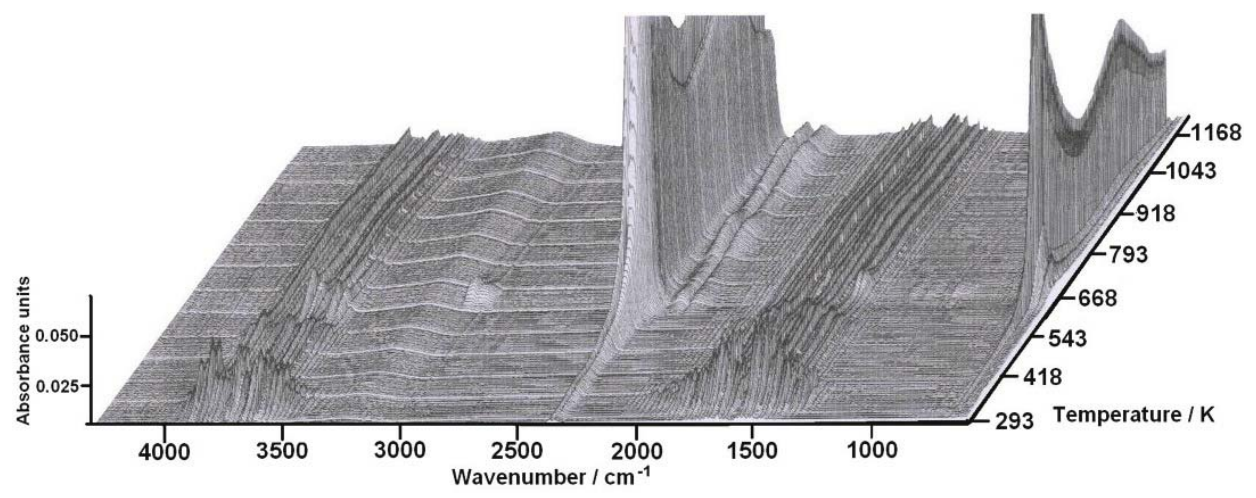

Fig. 3. Stacked plot of FT-IR spectra of evolved gas products of $\mathrm{Nd}_{2} \mathrm{~L}_{3} \cdot 9 \mathrm{H}_{2} \mathrm{O}$.

The way of metal- $\mathrm{COO}^{-}$coordination in the carboxylate complexes is often determined from the IR spectra of carboxylate complexes and sodium salt of this ligand taking into consideration spectroscopic Nakamoto criteria. Therefore the salt of this acid must be thoroughtly defined. So, the disodium 2,3-pirydinedicarboxylate was obtained as the monohydrate crystalline compound $\mathrm{Na}_{2}(\mathrm{PDC}) \cdot \mathrm{H}_{2} \mathrm{O}$ (Fig. 4).

The thermo-gravimetric analysis of $\mathrm{Na}_{2}(\mathrm{PDC}) \cdot \mathrm{H}_{2} \mathrm{O}$ exhibits three weight-loss steps. The lower temperature weight change of $8 \%$ (calc. 7.9 $\%$ ) between 393-453 K corresponds to the dehydration of sodium salt with the loss of one molecule of water. The value of dehydration enthalpy is $50 \mathrm{~kJ} \mathrm{~mol}^{-1}$. After dehydration the anhydrous compound is stable up to about $673 \mathrm{~K}$. 


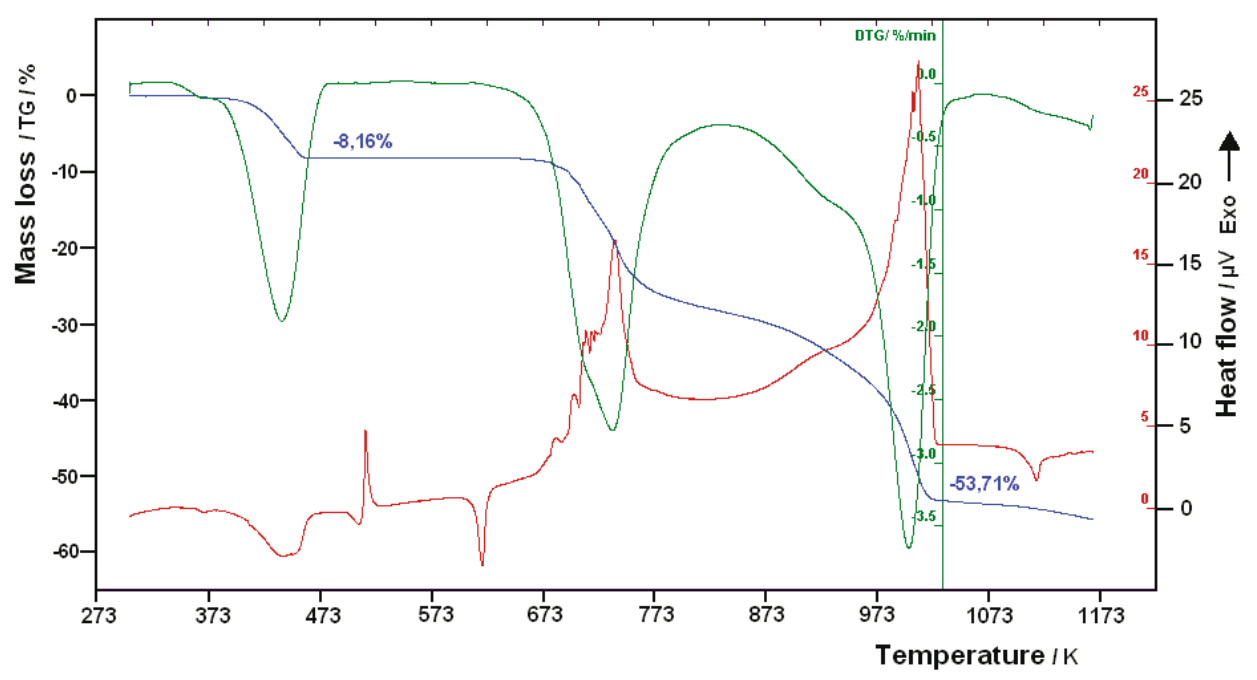

Fig. 4. TG and DSC curves of decomposition of $\mathrm{Na}_{2} \mathrm{~L} \cdot \mathrm{H}_{2} \mathrm{O}$.

The dehydration does not destroy the crystallity of the salt, but X-ray diffraction pattern is significantly different from that of the hydrated salt (Fig. 5). Further heating causes the gradual decomposition of anhydrous salt, two steps of mass loss are at about $723 \mathrm{~K}$ and about $973 \mathrm{~K}$.

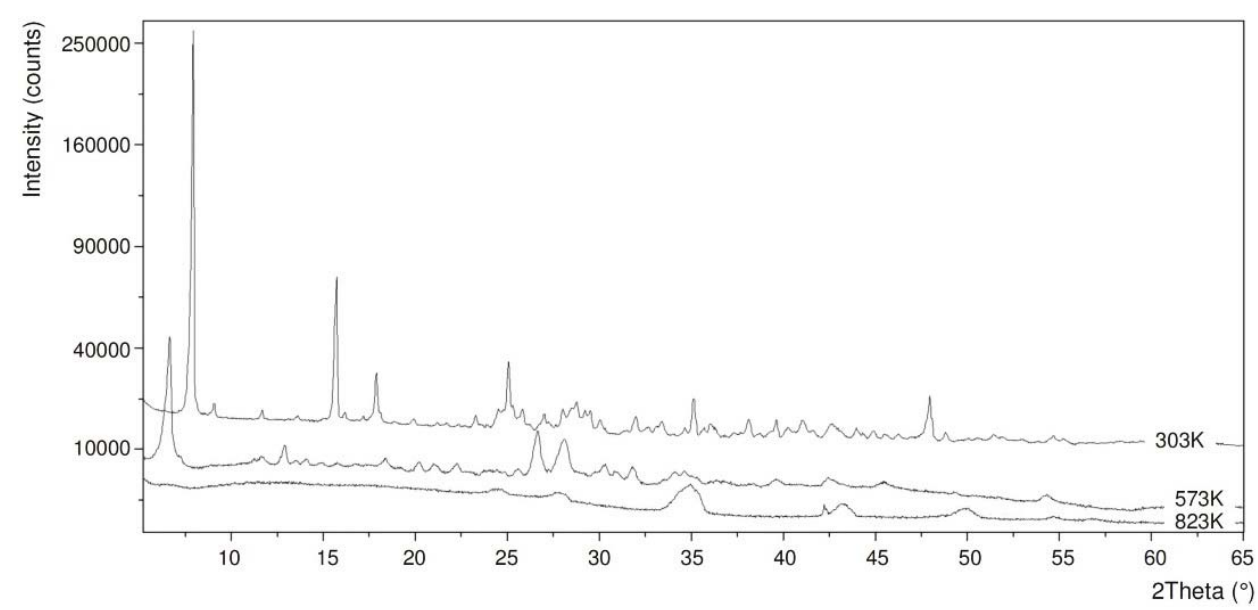

Fig. 5. XRD patterns of $\mathrm{Na}_{2} \mathrm{~L} \cdot \mathrm{H}_{2} \mathrm{O}$ and decomposition products: $\mathrm{Na}_{2} \mathrm{~L}$ and $\mathrm{Na}_{2} \mathrm{CO}_{3}$.

The observed mass loss is $54.5 \%$ what corresponds to formation of sodium carbonate. X-ray diffraction pattern for the sample at $823 \mathrm{~K}$ fits well those of sodium carbonate reported in the literature [ICDD 4-9- 
8630]. At $1023 \mathrm{~K}$ the whole amount of the substance forms $\mathrm{Na}_{2} \mathrm{CO}_{3}$, so the TG shows plateau. The melting point of formed disodium carbonate is visible at $1123 \mathrm{~K}$ (literature data $1124 \mathrm{~K}$ ) [40, 41]. Up to melting point, the weight loss of $\mathrm{Na}_{2} \mathrm{CO}_{3}$ is extremely slow creating $\mathrm{Na}_{2} \mathrm{O}$ and $\mathrm{CO}_{2}$.

\section{CONCLUSIONS}

Light lanthanide complexes with 2,3-pyridinedicarboxylate anion were obtained as hydrated compounds of the formulae $\operatorname{Ln}_{2}\left\{\mathrm{C}_{5} \mathrm{H}_{3} \mathrm{~N}\right.$ $\left.(\mathrm{COO})_{2}\right\}_{3} \cdot n \mathrm{H}_{2} \mathrm{O}$, where the number of water molecules was six for $\mathrm{Eu}$, eight for La, Ce, Pr, Sm and nine for Nd, Gd(III) compounds. Dehydration process takes place in one or two steps. This way of dehydration process pointed out that water molecules are bonded in inner and outer spheres of the obtained complex. Taking into consideration that coordination way of lanthanide ion to carboxylate groups are chelating and bridging, the central ion may coordinate five oxygen atoms from carboxylate groups and probably four of water molecules. So the formula of complex should be $\left[\mathrm{Ln}_{2}(\mathrm{PDC})_{3}\left(\mathrm{H}_{2} \mathrm{O}\right)_{4}\right] \cdot 2-5 \mathrm{H}_{2} \mathrm{O}$.

The compounds, after removing water molecules are stable at a higher temperature up to 573-673 K. The thermal stability in connection with crystallinity after water molecules removing, is the most important factor which conditions application of pyridinedicarboxylates as compounds for the MOF-like structure synthesis.

\section{REFERENCES}

[1] U. Ravon, M. Savonnet, S. Aguado, M.E. Domine, E. Janneau, D. Ferrusseng, Microporous Mesoporous Mater., 129, 319, (2010).

[2] A. Szorcsik, L. Nagy, A. Deák, M. Scopelliti, Z.A. Fekate, A. Császár, C. Pellerito, L. Pellerito, J. Organomet. Chem., 689, 2762, (2004).

[3] L.K. Hou, F.Y. Bai, Y.H. Xing, Y.Z. Cao, D.M. Wei, S.Y. Niu, J. Inorg. Organomet. Polym., 10.10007/s10904-010-9441-y, (2010).

[4] C. Qin, X. Wang, E. Wang, L. Xu, Inorg. Chim. Acta, 359, 417, (2006).

[5] A. Szorcsik, L. Nagy, J. Sletten, G. Szalontai, E. Kamu, T. Fiore, L. Pellerito, E. Kálmán, J. Organomet. Chem., 689, 1145, (2004).

[6] X. Gu, D. Xue, H. Ratajczak, J. Mol. Struct., 887, 56, (2008). 
[7] S.Q. Xia, S. Hu, J.C. Dai, T.X. Wu, J.J. Zhang, Z.Y. Fu, W.X. Du, Inorg. Chem. Commun., 7, 51, (2004).

[8] X. Zhu, S. Gao, Y. Li, H. Yang, G. Li, B. Xu, R. Cao, J. Solid State Chem., 182, 421, (2009).

[9] Z. Hnatejko, G. Dutkiewicz, M. Kubicki, S. Lis, J. Mol. Struct., 1034, 128, (2013).

[10] J.C. Yao, J.B. Guo, J.G. Wang, Y.F. Wang, L. Zhang, C.P. Fan, Inorg. Chem. Commun., 13, 1178, (2010).

[11] Y.S. Song, B. Yan, Z.X. Chen, Inorg. Chim. Acta, 360, 3431, (2007).

[12] X. Wang, C. Qin, E. Wang, Y. Li, N. Hao, C. Hu, L. Xu, Inorg. Chem., 43, 1850, (2004).

[13] A. Kvick, T.F. Koetzle, R. Thomas, F. Tukusagawa, J. Chem. Phys., 60, 3866, (1974).

[14] K.M. Harmon, K.E. Shaw, J. Mol. Struct., 513, 219, (1999).

[15] H. Briehl, J. Butenuth, Thermochim. Acta, 211, 121, (1992).

[16] H. Briehl, J. Butenuth, Thermochim. Acta, 167, 249, (1990).

[17] L. Campanella, T. Ferri, P. Mozzani, J. Inorg. Nucl. Chem., 41, 1054, (1979).

[18] K.M. Harmon, P.W. Brown, S.H. Gill, J. Mol. Struct., 448, 43, (1998)

[19] B. Barszcz, M. Hodorowicz, A. Jabłońska-Wawrzycka, J. Masternak, W. Nitek, K. Stadnicka, Polyhedron, 29, 1193, (2010).

[20] Y. Kang, J. Zhang, Z.J. Li, J.K. Cheng, Y.G. Yao, Inorg. Chim. Acta, 59, 2201, (2006).

[21] M.A.S. Goher, A.A. Youssef, Z-Y. Zhou, T.C.W. Mak, Polyhedron, 12, 1871, (1993).

[22] Z.T. Yu, G.H. Li, Y.S. Jiang, J.J. Xu, J.S. Chen, Dalton Trans., 4219 (2003).

[23] Z.T. Yu, Z.L. Liao, Y.S. Jiang, Chem. Commun., 1814 (2004).

[24] C.X. Zhang, C.B. Ma, M. Wang, C.N. Chen, Chin. J. Struct. Chem., 27, 1370, (2008).

[25] L.J. Li, Y. Li, J. Mol. Struct., 694, 199, (2004).

[26] M.A.S. Goher, A.A. Youssef, F.A. Mautner, Polyhedron, 25, 1531, (2006).

[27] M.G.B. Drew, R.W. Matthews, R.A. Walton, J. Chem. Soc. A, 2959, (1971).

[28] B.O. Patrick, C.L. Stevens, A. Storr, Polyhedron, 22, 3025, (2003). 
[29] F. Jaber, F. Charbannier, R. Faure, Polyhedron, 15, 2909, (1996).

[30] Q. Yue, J. Yang, G.H. Li, G.D. Li, W. Xu, J.S. Chen, S.N. Wang, Inorg. Chem., 44, 5241, (2005).

[31] S.A. Cotton, CR Chimie, 8, 129, (2005).

[32] P. Mahata, G. Sankar, G. Madras, S. Natarajan, Chem. Commun., 5787 (2005),

[33] W. Brzyska, W. Ożga, J. Therm. Anal. Calorim., 288, 113, (1996).

[34] W. Brzyska, W. Ożga, J. Therm. Anal. Calorim., 273, 205, (1996).

[35] Z. Rzączyńska, A. Danczowska-Burdon, J. Therm. Anal. Calorim., 108, 991, (2012).

[36] Z. Rzączyńska, A. Danczowska-Burdon, J. Sienkiewicz-Gromiuk, J. Therm. Anal. Calorim., 101, 671, (2010).

[37] R. Łyszczek, J. Anal. Appl. Pyrolysis, 86, 239, (2009).

[38] S. Siekierski, J. Inorg. Nucl. Chem., 43, 3381, (1981).

[39] J.C. Bailar, H.J. Emeléus, R. Nyholm, A.F. Trotman-Dickenson, Comprehensive inorganic chemistry (Pergamon Press Ltd., England, 1973)

[40] J.W. Kim, Y.D. Lee, H.G. Lee, ISIJ Int., 41, 116, (2001).

[41] M.D. Judd, B.A. Plunkett, M.I. Pope, J. Therm. Anal., 6, 555, (1974). 